\title{
QUALIDADE DE GRÃOS DE MILHO SUBMETIDOS À SECAGEM COM LENHA E POSTERIORMENTE ARMAZENADOS EM AMBIENTE NATURAL
}

\author{
RAFAEL FRIEDRICH DE LIMA ${ }^{1}$, ARNALDO TIECKER JUNIOR ${ }^{1}$, \\ PAULO RICARDO DE JESUS RIZZOTO JÚNIOR ${ }^{1}$, \\ RAFAEL GOMES DIONELLO e LAURI LOURENÇO RADUNZ ${ }^{1}$
}

\begin{abstract}
${ }^{1}$ Universidade Federal do Rio Grande do Sul (UFRGS), Faculdade de Agronomia, Departamento de Fitossanidade. Av. Bento Gonçalves, 7712, Caixa Postal 15100, CEP 91540-000. Fone (51) 3308-7404, Porto Alegre, RS, Brasil, rafaellimars@hotmail.com,tiecker@hotmail.com,paulo_rizzoto@hotmail.com, rafdionello@hotmail.com,laurilr@hotmail.com
\end{abstract}

Revista Brasileira de Milho e Sorgo, v.15, n.3, p. 594-606, 2016

\begin{abstract}
RESUMO - Com a finalidade de avaliar os efeitos imediatos e latentes da secagem com altas temperaturas, usando lenha como combustível, nas qualidades física, química e tecnológica de grãos de milho, foram utilizadas três temperaturas do ar de secagem: $60^{\circ} \mathrm{C}, 60 / 80^{\circ} \mathrm{C}$ e $80{ }^{\circ} \mathrm{C}$. As análises realizadas foram de: peso de 1.000 grãos, massa específica, umidade, análises químicas de proteína bruta, acidez titulável, material mineral e análise de defeitos nos grãos. O estudo foi conduzido conforme o delineamento inteiramente casualizado, em esquema fatorial, sendo os dados submetidos à análise de variância e, posteriormente, ao teste de Tukey e à análise de regressão. Com base nos resultados obtidos, concluiu-se que: 1. A massa específica dos grãos de milho apresentou redução de forma direta com os incrementos da temperatura de secagem e do tempo de armazenagem; 2. As reduções do peso de 1.000 grãos e do incremento de avariados ocorreram em função do tempo de armazenamento; 3. O percentual de grãos carunchados foi menor nas maiores temperaturas de secagem, porém com incremento ao longo do período de armazenagem, exceto para a secagem a $80{ }^{\circ} \mathrm{C} ; 4$. Ao longo do tempo de armazenagem, foram observados incrementos na acidez do óleo e na material mineral, com maiores valores, ao final da armazenagem, naqueles grãos submetidos a maior temperatura do ar de secagem.
\end{abstract}

Palavras-chave: Zea mays; secagem com altas temperaturas; efeitos latente e imediato.

\section{QUALITY OF MAIZE GRAINS SUBMITTED TO FIREWOOD DRYING AND STORED UNDER NATURAL ENVIRONMENT}

\begin{abstract}
ABTRACT - In order to assess the immediate and latent effects of drying at high temperatures (using wood as fuel) on the physical, chemical and technological quality of maize grains, three temperatures were used for drying: $60^{\circ} \mathrm{C}$, $60 / 80^{\circ} \mathrm{C}$ and $80^{\circ} \mathrm{C} .:$ Grain weight, density, moisture, chemical analysis of crude protein, acidity, mineral material, and defects in grains were evaluated. The study used a completely randomized design in a factorial scheme, and the data were submitted to analysis of variance. Tukey test and regression analysis were subsequently performed. The results showed that: 1 . The specific mass of the corn grains decreased directly with increasing drying temperature and storage time; 2. Reduction in the thousand kernel weight and increase in damaged grains occurred with increasing storage time; 3 . The percentage of rotten grains was lower in higher drying temperatures, but was higher as the storage period increased, except for drying at $80^{\circ} \mathrm{C} ; 4$. During the storage period, increases in acidity of the oil and mineral material were observed, with higher values at the end of storage period for those grains subjected to higher drying temperature.
\end{abstract} Keywords: Zea mays; drying at high temperatures; latent and immediate effect. 
O Brasil é o terceiro maior produtor mundial de milho, sendo superado apenas pelos Estados Unidos e pela China (USDA, 2016). Na safra de 2014/2015, foram produzidas 84,672 milhões de toneladas e com estimativa de colheita da safra 2015/2016 de 69,14 milhões de toneladas (CONAB, 2016).

Conforme Brum e Luft (2008), no Brasil, de $70 \%$ a $80 \%$ de todo o milho produzido é destinado à ração animal, enquanto apenas $1,6 \%$ é processado industrialmente para alimentação humana, sendo que, do milho destinado ao consumo animal, 54,8\% é utilizado no setor avícola, $36,1 \%$ na suinocultura, 7,2\% na pecuária e $1,9 \%$ no setor de pets, o qual vem crescendo rapidamente no país.

O produtor que optar pela segunda safra (inverno) deverá estar mais atento com relação à secagem desses grãos. Essas precauções devem ser intensificadas, uma vez que grãos oriundos da safra de inverno são colhidos em períodos em que há aumento de umidade do ar, ou seja, durante o período que vai de abril/maio até setembro. Portanto, tornase mais difícil usar o ar natural sem aquecimento como forma de secagem, principalmente na região Sul do país.

A utilização de secadores com altas temperaturas é a principal maneira de retirar água dos grãos em um tempo relativamente curto, empregando-se como combustíveis, geralmente, a lenha, o gás liquefeito de petróleo (GLP) e a casca de arroz.

Porém, quando a retirada de água é realizada de forma muito acelerada, podem ocorrer danos irreversíveis nos grãos. Os danos mais frequentes, causados quando a secagem por ar aquecido não é convenientemente controlada, são alterações de cor, formação de crosta periférica, perda de matéria seca, redução da integridade física dos grãos, diminuição da diges- tibilidade das proteínas, desestruturação do amido, suscetibilidade à incidência de defeitos e redução da conservabilidade, além do desperdício de tempo e de energia (Elias, 2002).

A secagem com uso de lenha como combustível é a mais utilizada no Brasil, principalmente em função do seu baixo custo (Weber, 2005) e da fácil obtenção. Porém, o controle da temperatura do ar de secagem é bem mais difícil, com variações maiores e, consequentemente, maiores riscos de danos nos grãos.

Os danos nos grãos decorrentes de má secagem podem ocorrer logo após o processo de secagem, definido como danos imediatos, ou danos que se manifestarão ao longo do armazenamento, ditos danos latentes. A maior ou a menor intensidade de dano está relacionada com a espécie e a cultivar e depende da interação entre as temperaturas do ar de secagem e da umidade inicial do produto (Fleurat-Lessard, 2002).

Segundo Silva (2008), grãos de milho que tenham como finalidade a obtenção de amido podem ser aquecidos a até $55{ }^{\circ} \mathrm{C}$ e, se forem destinados à indústria de ração, podem chegar a até $82{ }^{\circ} \mathrm{C}$, sem comprometer a qualidade para a qual se destinam. Já para sementes de milho, a temperatura máxima não deve ultrapassar os $44{ }^{\circ} \mathrm{C}$. Os mesmos autores afirmam que grãos de milho que são aquecidos acima de $60{ }^{\circ} \mathrm{C}$ têm seu endosperma modificado, o que poderia afetar a taxa de extração de amido.

Os danos latentes, ocasionados pela temperatura do ar de secagem, que são observados ao longo do armazenamento, são mensuráveis através da qualidade dos grãos. Os fatores que podem modificar a qualidade são a temperatura, a umidade dos grãos, a umidade relativa do ar, a atmosfera de armazenamento, os grãos quebrados, as impurezas, a presença de microrganismos, os insetos e os ácaros, além do tempo de armazenamento (Paraginski, 2013). 
Segundo Bakker-Arkema (1994), para avaliar a qualidade dos grãos, consideram-se diversas propriedades qualitativas, como teor de água, massa específica, percentual de grãos quebrados, impurezas e matérias estranhas, susceptibilidade à quebra, qualidade de moagem, conteúdo de proteínas, valor como ração, viabilidade como semente, presença de insetos e de fungos. Além dessas citadas pelo autor, destacam-se a acidez, a material mineral, o teor de carboidratos, os contaminantes (micotoxinas), o peso de 1.000 grãos, além de outras análises que possam medir as características químicas, físicas, biológicas e fisiológicas dos grãos.

Conforme exposto anteriormente, o presente estudo teve como objetivo avaliar a qualidade de grãos de milho submetidos à secagem com altas temperaturas, em secador do tipo coluna, empregando como combustível a lenha, com posterior armazenagem durante nove meses.

\section{Material e Métodos}

O estudo foi realizado na Estação Experimental Agronômica da Universidade Federal do Rio Grande do Sul (EEA/UFRGS), no município de Eldorado do Sul, RS (30 05' 52” S, 51 39'08' W e altitude média de $46 \mathrm{~m}$ ), localizada no km 146 da rodovia BR 290.

Foram utilizados grãos de milho (Zea mays L.) do híbrido Pioneer Yieldgard 30K75Y, segunda safra, ano agrícola 2012/2013, cultivados no mesmo local de realização do estudo.

Os grãos foram colhidos com colhedora automatizada, com umidade de aproximadamente 30\%, no dia 01 de junho de 2012. Após, os grãos foram previamente limpos em máquina de pré-limpeza, equipada com dois conjuntos de peneiras e, posteriormente, secos em secador de coluna (Figura 1).

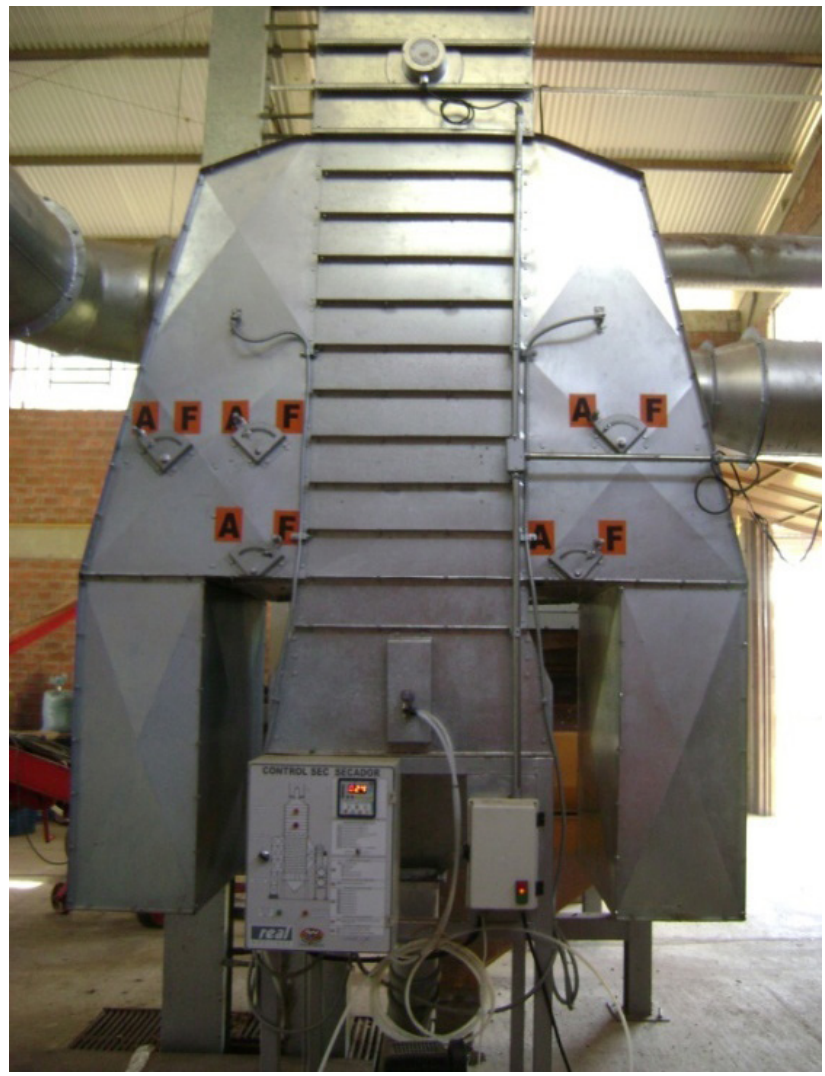

Figura 1. Secador de coluna, com fluxo cruzado de ar, utilizado para a secagem dos grãos. Eldorado do Sul, RS, 2012.

O fluxo de ar no secador foi do tipo cruzado, com a massa de grãos sempre em constante movimento. A cada $40 \mathrm{seg}, 35 \mathrm{~kg}$ de grãos, que estavam na câmara de secagem, eram descarregados em elevador do tipo caneca e transportados até o topo do secador, para novamente passar pela câmara de secagem. Dessa forma, a cada 8,2 min, os grãos concluíam um ciclo de passagem pelo secador. Esse fluxo de grãos foi mantido durante todo o processo de secagem, até os grãos atingirem a umidade final desejada.

Para condução do experimento, foram empregados dois secadores com plena carga, com capacidade individual de $720 \mathrm{~kg}$ de grãos de milho. Foram avaliadas três temperaturas para secagem, 
sendo: $\mathrm{T} 1=60 \pm 5^{\circ} \mathrm{C}$, durante todo período de secagem; T2 $=60 / 80 \pm 5{ }^{\circ} \mathrm{C}$, ou seja, nas primeiras $4 \mathrm{~h}$ de secagem a temperatura foi de $60 \pm 5^{\circ} \mathrm{C}$ e no restante do tempo de $80 \pm 5^{\circ} \mathrm{C}$; e T3 $=80 \pm 5^{\circ} \mathrm{C}$, durante todo o período de secagem. $\mathrm{O}$ ar foi aquecido através da queima de lenha da espécie eucalipto, com diâmetro de até $20 \mathrm{~cm}$ e com umidade média de $32 \%$ b.u..

Durante as operações de secagem, foi realizado o monitoramento do teor de água dos grãos com uso do determinador dielétrico (GEOLE), previamente calibrado pelo método de estufa, sendo retiradas amostras em intervalos de tempo de 30 min até o final da operação, quando os grãos encontravam-se com $13 \%$ de umidade. Ao final das operações de secagem e durante o armazenamento, todas as determinações de umidade foram realizadas em estufa a $105+3{ }^{\circ} \mathrm{C}$, com circulação natural de ar (Brasil, 2009).

Dados referentes às temperaturas do ar de entrada e de saída do secador, à temperatura da massa de grãos, à umidade relativa do ambiente e à temperatura do ambiente foram obtidos a cada $30 \mathrm{~min}$. As temperaturas do ar de entrada e de saída do secador foram monitoradas com termômetro de mercúrio, localizado no próprio secador. Já a umidade e a temperatura do ambiente foram monitoradas com aparelho termo-higrômetro. A temperatura da massa de grãos foi medida com termômetro de mercúrio, em amostras coletadas na descarga do secador. Os grãos eram depositados num copo de isopor e, logo em seguida, era inserido um termômetro na massa de grãos para medir a temperatura dos mesmos.

Depois de finalizada a operação de secagem, os grãos oriundos de cada temperatura de secagem foram homogeneizados e, logo em seguida, armazenados em 22 sacos para cada tratamento de secagem. $\mathrm{O}$ armazenamento teve início no dia 10 de junho de 2012, mantendo-se as sacarias em galpão de alvena- ria, com piso impermeável, sobre estruturas de madeira do tipo palete, permanecendo nestas condições durante nove meses.

\section{Análises}

Para realização das análises, as amostras foram obtidas com auxílio de calador, obtendo-se aproximadamente $30 \mathrm{~g}$ de grãos de cada saco, conforme descrito na IN 60/2011 (Brasil, 2011).

As coletas das amostras foram realizadas imediatamente ao início da armazenagem (tempo zero) e, posteriormente, em intervalos trimestrais, até o período final de condução do experimento, que ocorreu aos nove meses da instalação, ou seja, em 10 de março de 2013, exceto a análise de acidez, que foi realizada até o sexto mês.

As análises físicas, químicas e tecnológicas foram realizadas nos Departamentos de Fitossanidade e de Zootecnia da UFRGS, sendo executadas conforme descrito a seguir:

\section{$\underline{\text { Teor de água }}$}

A determinação do teor de água foi realizada pelo método de estufa a $105 \pm 3{ }^{\circ} \mathrm{C}$, com circulação natural de ar, por $24 \mathrm{~h}$, conforme apresentado nas Regras para Análise de Sementes (Brasil, 2009). Os resultados foram expressos em percentagem (\%) de água, em base úmida.

\section{Massa específica}

Determinada através da pesagem dos grãos em balança eletrônica com precisão de $0,001 \mathrm{~g}$, a partir de uma balança de peso hectolitro com volume de 250 $\mathrm{cm}^{3}$. Os resultados da massa específica foram convertidos, para serem expressos em $\mathrm{kg} \mathrm{m}^{-3}$, em base seca.

\section{$\underline{\text { Peso de } 1.000 \text { grãos }}$}

O peso de 1.000 grãos foi determinado através da pesagem de oito repetições de 100 grãos em balan- 
ça analítica, calculando-se a média e multiplicandose o resultado obtido por 10 (Brasil, 2009).

Proteína bruta

O teor de proteína bruta foi obtido pelo método Kjeldahl, descrito pela American Association of Cereal Chemists (2000). Os resultados foram expressos em percentual de base seca.

\section{Material mineral ou cinzas}

O teor de cinzas ou de material mineral foi determinado conforme descrito na Association of Official Analytical Chemistry (1990), com incineração prévia e calcinação em mufla a $560-580{ }^{\circ} \mathrm{C}$, até peso constante. Os resultados foram expressos em percentual de base seca.

\section{Acidez do extrato etéreo dos grãos}

O teor de acidez dos grãos foi determinado por titulação, com solução de hidróxido de sódio $0,01 \mathrm{~N}$, do extrato etéreo em solução de éter/álcool na proporção de $2: 1$, previamente aquecido para diluir a gordura contida nos frascos.

A acidez foi expressa em percentual de ácido oleico, a partir da seguinte equação, conforme descrito pela A.O.C.S. (1996).

$$
\frac{\mathrm{V} * \mathrm{f} * 100 * 0,0282}{\mathrm{P}}=\text { acidez em \% ácido oleico }
$$

Onde:

$\mathrm{V}=$ quantidade de solução de hidróxido de sódio $0,01 \mathrm{~N}$ gasto na titulação $(\mathrm{mL})$

$\mathrm{f}=$ fator de normalidade da solução de hidróxido de sódio $0,1 \mathrm{~N}$

$\mathrm{P}=$ massa da amostra $(\mathrm{g})$

Análise tecnológica

Os grãos avariados (ardidos, chochos ou imaturos, fermentados, germinados, gessados e mofados), os carunchados, as matérias estranhas e as impurezas e os quebrados foram determinados pela metodologia descrita na instrução normativa $\mathrm{n}^{0} 60$, de 22 de dezembro de 2011 (Brasil, 2011).

\section{Planejamento experimental}

O estudo foi conduzido conforme o delineamento inteiramente casualizado, em esquema fatorial $3 \times 4$ (temperatura de secagem $\mathrm{x}$ tempo de armazenamento), com duas repetições.

Os dados foram submetidos à análise de variância, através do teste $\mathrm{F}(\mathrm{P} \leq 0,05)$ e, quando acusado efeito significativo, foi realizado o teste de Tukey para o fator qualitativo $(\mathrm{P} \leq 0,05)$ e a análise de regressão para o fator quantitativo, com auxílio dos softwares Assistat 7.7 e SigmaPot 10.0.

\section{Resultados e Discussão}

As médias do tempo de secagem e da temperatura máxima da massa de grãos foram de 11,25; 10,0 e $8,0 \mathrm{~h} ; 38,5 ; 44$ e $48^{\circ} \mathrm{C}$ para as temperaturas de secagem de $60,60 / 80$ e $80{ }^{\circ} \mathrm{C}$, respectivamente. A média da umidade antes da secagem dos grãos foi de $28 \%$ e após a secagem de $13 \%$ b.u..

Conforme os resultados da análise de variância $(\mathrm{P}<0,05)$, foi verificado efeito significativo entre os fatores avaliados (temperatura de secagem e tempo de armazenamento) para as variáveis teor de água, massa de 1.000 grãos, percentual de grãos carunchados, acidez do óleo e matéria mineral. Já a massa específica e o percentual de grãos avariados não apresentaram efeito da interação, porém o primeiro apresentou efeitos da temperatura de secagem e do tempo de armazenamento, enquanto o último apenas do tempo de armazenamento. 
Conforme a Figura 2, os grãos de milho entraram em equilíbrio higroscópico numa faixa de 12 a $13 \%$, independentemente da temperatura de secagem empregada. A variação da umidade dos grãos durante o armazenamento é dependente da composição química dos grãos, dos fatores ambientais (temperatura e umidade relativa do ar), dos fatores genéticos, da temperatura de secagem e da histerese (Chen, 2000). Esta tendência, dos grãos entrarem em equilíbrio higroscópico, já foi verificada por outros pesquisadores (Alencar et al., 2009; Elias et al., 2009; Schuch et al., 2011; Tiecker et al., 2014).

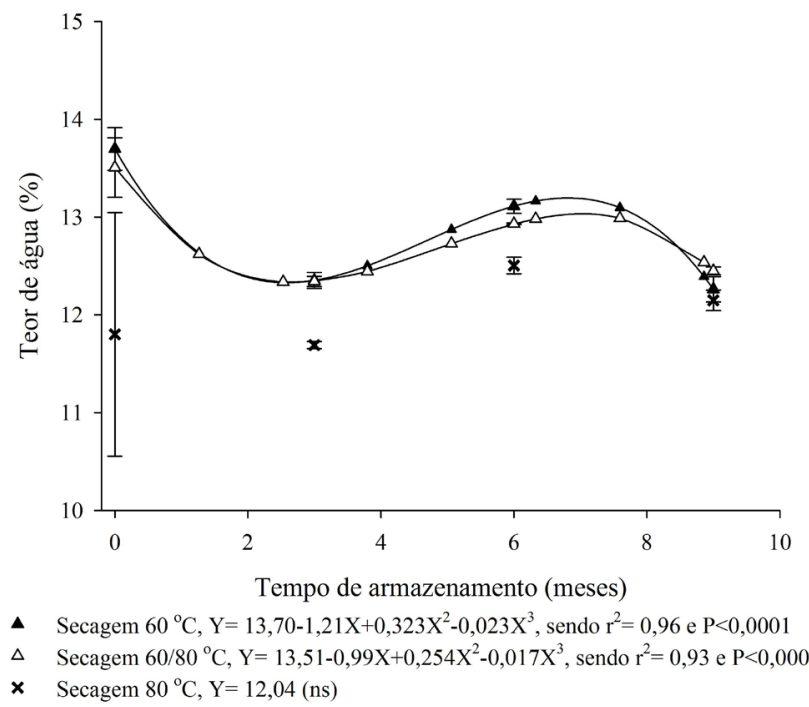

Figura 2. Teor de água de grãos de milho submetidos a diferentes temperaturas do ar de secagem e, posteriormente, armazenados durante nove meses em ambiente natural.

Na Tabela 1, estão os valores da massa específica dos grãos de milho em função da temperatura de secagem utilizada, em que a secagem com ar a $60{ }^{\circ} \mathrm{C}$ proporcionou menor redução da mesma, em comparação com as outras duas temperaturas de secagem, independentemente do tempo de armazenamento.
Tabela 1. Massa específica dos grãos de milho submetidos a diferentes temperaturas do ar de secagem e, posteriormente, armazenados por nove meses em ambiente natural.

\begin{tabular}{cc}
\hline $\begin{array}{c}\text { Temperatura do ar } \\
\text { de secagem }\left({ }^{\circ} \mathrm{C}\right)\end{array}$ & Massa específica \\
\hline 60 & $787,82 \mathrm{a}$ \\
$60 / 80$ & $775,15 \mathrm{~b}$ \\
80 & $764,52 \mathrm{c}$
\end{tabular}

Médias seguidas de letras distintas diferem estatisticamente entre si, conforme o teste de Tukey $(\mathrm{P} \leq 0,005)$. $\mathrm{CV}=0,61 \%$.

Também ao longo do tempo de armazenagem, a massa específica sofreu redução, independentemente da temperatura do ar de secagem, conforme demonstrado na Figura 3.

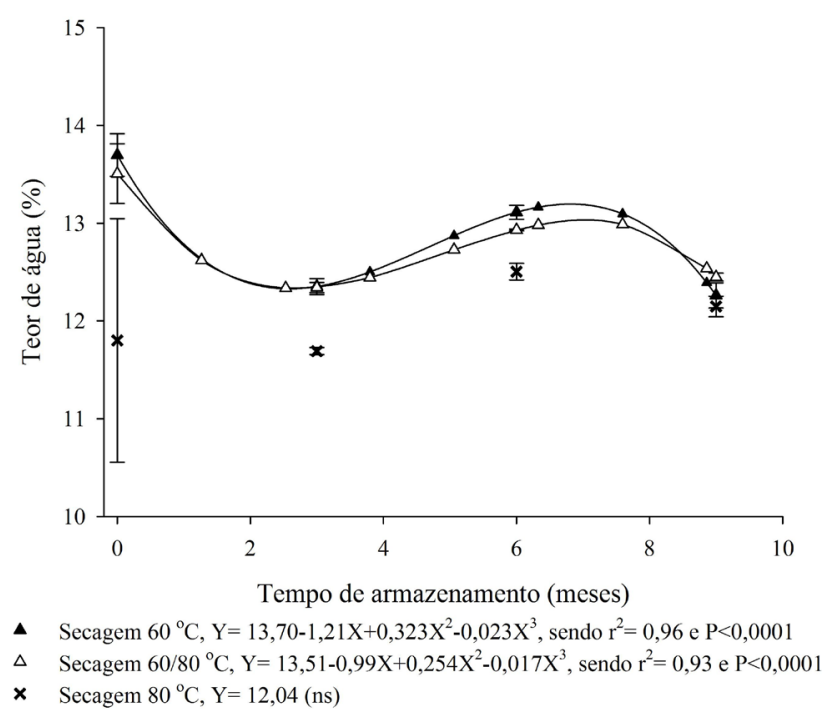

Figura 3. Massa específica de grãos de milho, durante nove meses de armazenamento em ambiente natural, em função da secagem nas temperaturas do ar de $60,60 / 80$ e $80{ }^{\circ} \mathrm{C}$.

Conforme os resultados apresentados na Tabela 1, a massa específica dos grãos sofreu redução dire- 
tamente proporcional ao incremento da temperatura do ar de secagem. Os resultados corroboram com os obtidos por Coradi et al. (2016), que observaram que, na secagem de grãos de milho, quanto maior foram as temperaturas utilizadas, maior foi a redução da massa específica. O mesmo foi observado por Oliveira et al. (2010) na secagem de aveia branca e por Eichelberger e Portella (2003) na secagem de grãos de milho.

A redução da massa específica pode estar relacionada aos danos térmicos, como trincas e fissuras, que ocasionam a expansão do volume dos grãos e o aparecimento de espaços vazios, devido a maior tensão interna proporcionada pela elevação da temperatura, reduzindo assim o seu valor (Eichelberger \& Portella, 2003). Esta redução está associada à perda de qualidade em consequência dos processos de desidratação e de deterioração dos grãos; portanto, menores valores são encontrados em grãos que perderam mais matéria seca (Silva, 2008).

Ao longo do tempo de armazenagem, tanto a massa específica como o peso de 1.000 grãos de milho sofreram redução, conforme demonstrado nas Figuras 3 e 4, respectivamente. A massa específica apresentou redução de forma linear e o peso de 1.000 grãos exponencial, com maior expressão no terço inicial do período de armazenagem.

Os resultados de redução da massa específica e do peso de 1.000 grãos estão de acordo com os obtidos por Antunes et al. (2011), Paraginski et al. (2015), Santos et al. (2012) armazenando grãos de milho.

Essas reduções, segundo Antunes et al. (2011), podem ser atribuídas ao ataque de insetos, mas também, conforme Paraginski et al. (2015), ao aumento do processo respiratório dos grãos, bem como, segundo Santos et al. (2012), associadas ao aumen-

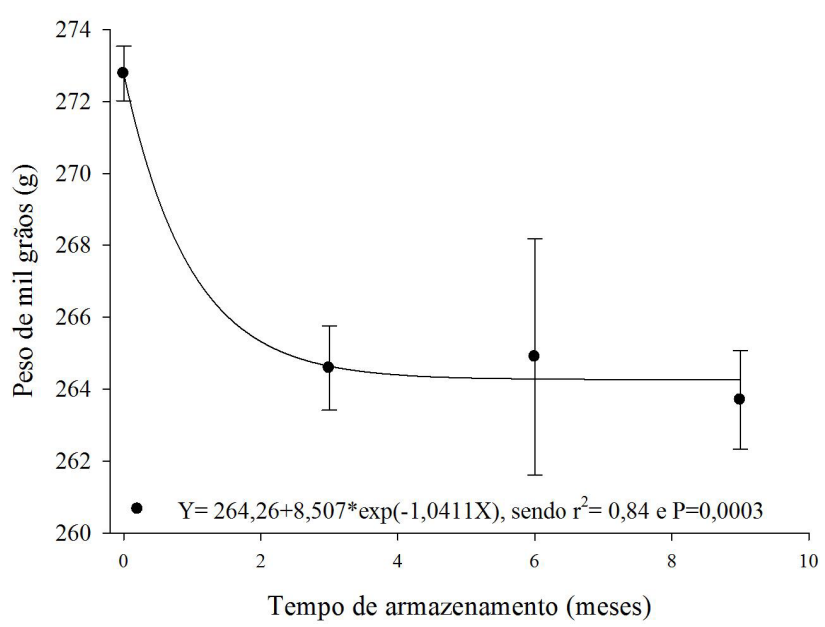

Figura 4. Massa de 1.000 grãos de milho, durante nove meses de armazenamento em ambiente natural, em função da secagem nas temperaturas do ar de 60 , $60 / 80$ e $80^{\circ} \mathrm{C}$.

to de volume devido ao ganho de água ou à perda de matéria seca. Como o teor de água dos grãos foi constante, supõem-se que as reduções verificadas estão relacionadas ao incremento do processo respiratório e ao consumo de parte dos grãos pelos insetos.

Schuch et al. (2011) avaliaram o peso de 1.000 grãos em milho, submetidos a secagem com ar natural e com GLP, quando observaram perdas significativas ao longo de nove meses de armazenamento, alcançando valores de aproximadamente $10 \%$ do peso. Conforme os referidos autores, estas perdas ocorrem, principalmente, devido ao ataque de pragas e à atividade respiratória dos próprios grãos.

No estudo da análise tecnológica, foram observados os grãos ardidos, os mofados, os fermentados, os germinados, os carunchados, os chochos ou imaturos e os gessados, conforme descrito na instrução normativa (IN) $n^{0}$ 60, de 2011 (Brasil, 2011). De acordo com esta IN, no total de avariados são contabilizados todos os defeitos, com exceção dos carunchados, que têm seus limites pré-definidos. 
Na Figura 5, é apresentado o total de grãos de milho avariados ao longo do armazenamento, mostrando incremento durante o período, independentemente da temperatura de secagem empregada.

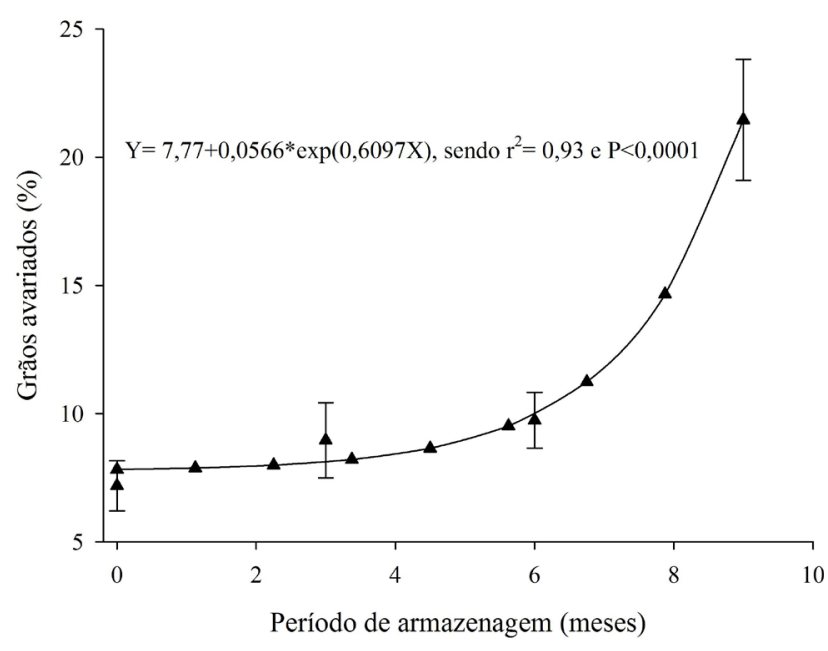

Figura 5. Percentual de grãos de milho avariados, submetidos a secagem nas temperaturas do ar de 60 , $60 / 80$ e $80^{\circ} \mathrm{C}$ e, posteriormente, armazenados durante nove meses em ambiente natural.

O maior aumento no percentual de grãos avariados ocorreu a partir do sexto mês de armazenamento (10 de dezembro), período em que o ar ambiente estava mais quente, proporcionando maior atividade dos microrganismos e dos insetos. Ainda que a umidade dos grãos não tenha aumentando significativamente, as condições do ambiente propiciaram o desenvolvimento de fungos, a tal ponto que era visível o mofo ou o bolor em alguns grãos. Os resultados corroboram com os obtidos por Antunes et al. (2011), ao armazenarem grãos de milho, quando concluíram que aos 120 dias os grãos se encontravam abaixo do nível padrão para comercialização.

De acordo com Mukanga et al. (2010), os gêneros de fungos mais importantes, associados aos grãos de milho, são Fusarium e Aspergillus. Foram encon- trados estes dois gêneros, além do Penicillium, durante o período de estocagem. As contaminações por micotoxinas no milho podem ocorrer em diferentes etapas de produção; dentre elas, no campo durante o cultivo, no processamento, no armazenamento ou no transporte (Coulibaly et al., 2008), sendo que condições de umidade e temperaturas elevadas favorecem o desenvolvimento durante o armazenamento.

Na Figura 6, são apresentados os resultados do percentual de grãos carunchados, em que se demonstra que os grãos secos com ar aquecido a $80{ }^{\circ} \mathrm{C}$ não apresentaram variação significativa ao longo do tempo, enquanto que os grãos submetidos às outras duas condições de secagem apresentaram incremento significativo de grãos carunchados ao longo do período de armazenagem.

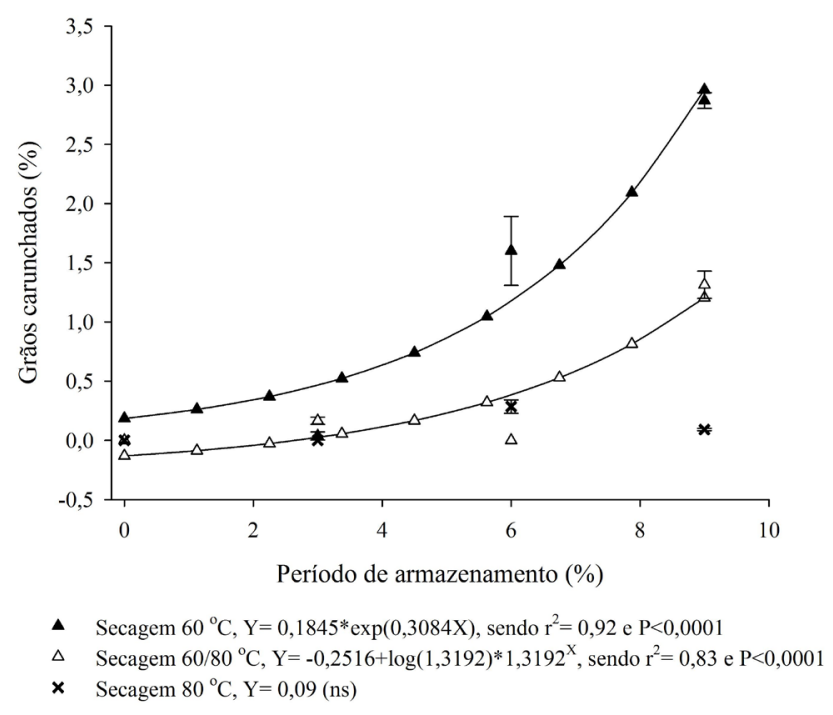

Figura 6. Percentual de grãos de milho carunchados submetidos a diferentes temperaturas do ar de secagem e, posteriormente, armazenados durante nove meses em ambiente natural.

Ao longo do armazenamento, os grãos foram atacados por insetos da espécie Sithophilus zeamais, conhecidos popularmente como carunchos ou gorgu- 
lhos do milho. A maior severidade ocorreu do sexto para o nono mês, coincidindo o período de armazenamento com temperaturas mais elevadas. Até o sexto mês, os grãos ainda estavam em condição menos propensa ao ataque dos insetos, visto que o período era de frio, ou seja, com temperaturas mais baixas. Os resultados de incremento corroboram com os obtidos por Antunes et al. (2011), que, ao estudarem grãos de milho infestado com $S$. zeamais, observaram valores de grãos carunchados de $9,77 \%$ aos 60 dias de armazenamento e, aos 120 dias, o percentual foi de 34,01\%.

Ferrari Filho et al. (2014), avaliando o efeito de diferentes fontes energéticas na secagem de grãos de milho, também verificaram um aumento de grãos carunchados após o sexto mês de armazenamento, período que coincidiu com uma estação mais quente e que propiciou este aumento na população de insetos e, por consequência, aumento deste tipo de defeito.

Já os grãos secos com ar aquecido a $80{ }^{\circ} \mathrm{C}$ não apresentaram variação significativa, ao longo do período de armazenagem, no número de grãos carunchados. Conforme Banks e Fields (1995), quando a temperatura da massa de grãos atinge valores entre 45 e $60{ }^{\circ} \mathrm{C}$, a morte dos insetos pode ocorrer em tempo inferior a um dia a menos de uma hora. Também Ferrari Filho et al. (2011) avaliaram a sobrevivência de $S$. zeamays a distintas temperaturas de secagem de grãos de milho, quando constataram que, na temperatura média da massa de grãos de $48^{\circ} \mathrm{C}$, após os $210 \mathrm{~min}$ de exposição, a probabilidade de sobrevivência foi de $0 \%$. Logo, é provável que a temperatura de secagem a $80{ }^{\circ} \mathrm{C}$ (temperatura média da massa de grãos a $48{ }^{\circ} \mathrm{C}$ ) tenha inibido ou até mesmo esterilizado os ovos de Sithophilus spp, pois estas condições perduraram por mais de $4 \mathrm{~h}$, controlando assim o crescimento populacional e, consequentemente, o dano aos grãos durante o armazenamento.
Para as temperaturas do ar de secagem de 60 e $60 / 80{ }^{\circ} \mathrm{C}$, aos nove meses de armazenagem, os grãos foram classificados como fora de tipo devido ao aumento de grãos avariados, dentre estes os grãos mofados e os fermentados. Este aumento, principalmente no período final de armazenamento, pode ter ocorrido em função do incremento da temperatura do ar ambiente, condições favoráveis para o desenvolvimento de fungos de armazenamento.

Nos resultados de acidez do óleo, foi observado aumento significativo para as três temperaturas de secagem ao longo do tempo de armazenamento (Figura 7).

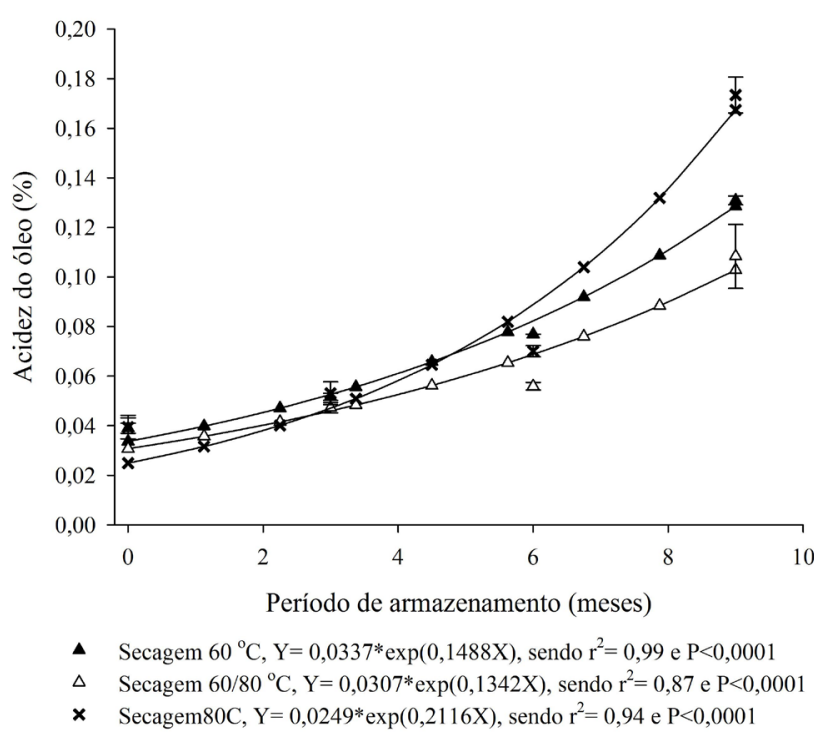

Figura 7. Acidez do óleo de grãos de milho submetidos a diferentes temperaturas do ar de secagem e, posteriormente, armazenados durante nove meses em ambiente natural.

$\mathrm{O}$ incremento de acidez observado no estrato etéreo dos grãos de milho corrobora com os resultados obtidos por Dionello et al. (2000) e por Elias et al. (2016), com grãos de milho e de feijão, respectivamente, armazenados em ambiente natural, em que 
observaram incremento da acidez do óleo ao longo do período de armazenamento.

Deliberali et al. (2010) verificaram aumento de acidez do óleo em grãos de aveia submetidos ao processo de secagem estacionário em relação à secagem intermitente. Os autores atribuíram o maior tempo de exposição ao calor como causa principal para este aumento. Tal comportamento pode ser observado no presente experimento quando comparamos os resultados iniciais de acidez entre as temperaturas, ou seja, na secagem em temperatura de $60^{\circ} \mathrm{C}$ a acidez foi maior que nas demais condições de secagem.

O aumento da acidez está diretamente correlacionado com a velocidade e a intensidade do processo deteriorativo dos grãos. A avaliação desse índice constitui-se em eficiente parâmetro para o controle da conservabilidade de grãos durante o armazenamento (Marini et al., 2005). Logo, o incremento de acidez observado indica que ocorreu degradação dos grãos ao longo do período de armazenagem para as três condições de secagem.

O teor de acidez informa o estado de conservação do óleo, quantifica as substâncias ácidas presentes e é um indicador de qualidade, ou seja, quanto menores os índices de acidez melhor é a qualidade do óleo (Borém et al., 2014).

A matéria mineral apresentou aumento ao longo do período de armazenagem, para as três temperaturas de secagem, com valor ligeiramente superior para a secagem com ar aquecido a $80^{\circ} \mathrm{C}$ (Figura 8).

Os resultados corroboram com os obtidos por Elias et al. (2009), Deliberali et al. (2010), Tiecker et al. (2014), que observaram aumento do teor de cinzas em grãos durante o tempo de armazenamento.

As atividades metabólicas dos grãos e dos microrganismos associados consomem a matéria orgânica, metabolizando-a até $\mathrm{CO}_{2}$, água e outros produ-

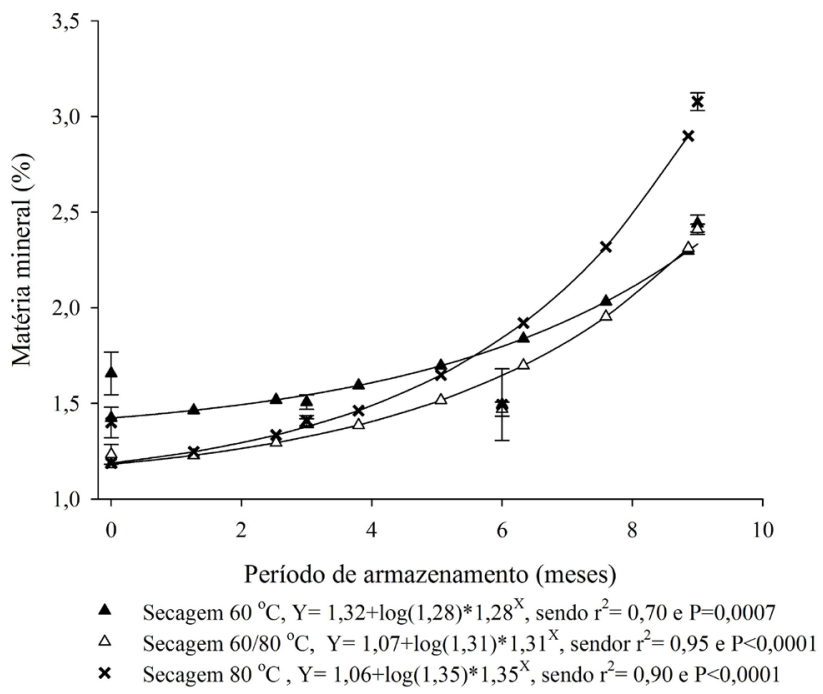

Figura 8. Material mineral de grãos de milho submetidos a diferentes temperaturas do ar de secagem e, posteriormente, armazenados durante nove meses em ambiente natural.

tos, com liberação de calor, podendo transformar estruturalmente a composição mineral sem alterar o seu conteúdo total. Desta forma, a determinação do teor de cinzas assume valores proporcionalmente maiores à medida que parte da matéria orgânica é consumida (Elias, 1998; Dionello et al., 2000). Assim, pode-se inferir que, independentemente da temperatura de secagem avaliada, ocorreu redução da qualidade dos grãos de milho durante o armazenamento, devido à redução do teor dos compostos orgânicos.

\section{Conclusões}

1. A massa específica dos grãos de milho apresentou redução de forma direta com os incrementos da temperatura de secagem e do tempo de armazenagem.

2. As reduções do peso de 1.000 grãos e do incremento de avariados ocorreram apenas em função do tempo de armazenamento, não tendo efeito significativo da temperatura do ar de secagem. 
3. O percentual de grãos carunchados foi menor nas maiores temperaturas de secagem, porém com incremento ao longo do período de armazenagem, exceto para a secagem a $80^{\circ} \mathrm{C}$, em que não foi observada variação significativa.

4. Ao longo do tempo de armazenagem, foram observados incrementos na acidez do óleo e na material mineral, com maiores valores, ao final da armazenagem, naqueles grãos submetidos a maior temperatura do ar de secagem.

5. Na secagem de grãos de milho, para as condições estudadas, a temperatura de $80{ }^{\circ} \mathrm{C}$ pode ser empregada, pois o principal fator de reduções quantitativa e qualitativa é o tempo de armazenagem.

\section{Referências}

ALENCAR, E. R. de; FARONI, L. R. D.; LACERDA FILHO, A. F.; PETERNELli, L. A.; COSTA, A. R. Qualidade dos grãos de soja armazenados em diferentes condições. Revista Brasileira de Engenharia Agrícola e Ambiental, Campina Grande, v. 13, n. 5, p. 606-613, 2009. DOI: $10.1590 / \mathrm{S} 1415-43662009000500014$.

AMERICAN ASSOCIATION OF CEREAL CHEMISTS. Approved methods AACC. 10th ed. St. Paul, 2000.

ANTUNES, L. E. G.; FERRARI FILHO, E.; TIECKER, A.; DIONELLO, R. G.; SPOLTI, P. Controle de gorgulhodo-milho submetido ao tratamento térmico. Revista Brasileira de Milho e Sorgo, Sete Lagoas, v. 10, n. 3, p. 196-204, 2011.

DOI: 10.18512/1980-6477/rbms.v10n3p196-204.

ASSOCIATION OF OFFICIAL ANALYTICAL CHEMISTRY. Official methods of analysis of the Association of Official Analytical Chemistry. 16. ed. Washington, 1990. v. 1/2.
BAKKER-ARKEMA, F. W. Grain quality and management of grain quality standards. In: INTERNATIONAL SYMPOSIUMOFGRAINCONSERVATION, 1993, Canela. Anais... Porto Alegre: Plus Comunicações, 1994. p. 3-11.

BANKS, H. J.; FIELDS, P. G. Physical methods for insect control in stored grain ecosystems. In: JAYAS, D. S.; WHITE, N. D. G.; MUIR, W. E. Stored grain ecosystems. New York: Marcell Dekker, 1995. p. 353-409.

BORÉM, F. M.; ISQUIERDO, E. P.; OLIVEIRA, P. D.; RIBEIRO, F. C.; IQUEIRA, V. C.; TAVEIRA, J. H. S. Effect of intermittent drying and storage on parchment coffee quality. Bioscience Journal, Uberlândia, v. 30, n. 2, p. 609-616, 2014.

BRASIL. Ministério da Agricultura Pecuária e Abastecimento. Regras para análise de sementes. Brasília, DF, 2009. 399 p.

BRASIL. Ministério da Agricultura Pecuária e Abastecimento. Instrução Normativa $n^{0}$ 60, de 22 de dezembro de 2011. Estabelece o Regulamento Técnico do Milho. Define o padrão oficial de classificação do milho, considerando seus requisitos de identidade e qualidade, a amostragem, o modo de apresentação e a marcação ou rotulagem, nos aspectos referentes à classificação do produto. Diário Oficial da União, Brasília, DF, 23 dez. 2011. Seção 1.

BRUM, A. L.; LUFT, A. Aspectos da cadeia produtiva do milho e as relações comerciais nos estados do Rio Grande do Sul e Mato Grosso (1994/95-2005/06). Revista Extensão Rural, Santa Maria, v. 15, n. 16, p. 117-143, 2008.

CHEN, C. Factors that affect equilibrium relative humidity of agricultural products. Transactions of the American Society of Agricultural and Engineers, v. 43, n. 3, p. 673683,2000

CONAB. Companhia Nacional de Abastecimento. Acompanhamento da safra brasileira de grãos: safra 2015/16. Brasília, DF, 2016. Disponível em: <http://www. conab.gov.br>. Acesso em: 29 ago. 2016. 
CORADI, P. C.; MILANE, L. V.; ANDRADE, M. G. O.; CAMILO, L. J.; SOUZA, A. H. S. Secagem de grãos de milho do cerrado em um secador comercial de fluxos mistos. Brazilian Journal of Biosystems Engineering, v. 10, n. 1, p. 14-26, 2016.

DOI: $10.18011 /$ bioeng2016v10n1p14-26.

COULIBALY, O.; HELL, K.; BANDYOPADHYAY, R.; HOUNKPONOU, S.; LESLIE, J. F. Economic impact of aflatoxin contamination in sub-Saharan Africa. In: LESLIE, J. F.; BANDYOPADYAY, R.; VISCONTI, A. (Ed.). Mycotoxins: detection methods, management, public health and agricultural trade. Wallingford: CAB International, 2008. p. 67-76.

DELIBERALI, J.; OLIVEIRA, M.; DURIGON, A.; DIAS, A. R. G.; GUTKOSKI, L. C.; ELIAS, M. C. Efeitos de processo de secagem e tempo de armazenamento na qualidade tecnológica de trigo. Ciência e Agrotecnologia, Lavras, v. 34, n. 5, p. 1285-1292, set./out. 2010. DOI: $10.1590 / \mathrm{S} 1413-70542010000500029$.

DIONELLO, R. G.; RADUNZ, L. L.; CONRAD, V. J. D.; LUCCA FILHO, O.; EliAS, M. C. Temperatura do ar na secagem estacionária e tempo de armazenamento na qualidade de grãos de milho. Revista Brasileira de Agrociência, Pelotas, v. 6, n. 2, p. 137-143, 2000.

EICHELBERGER, L.; PORTELlA, J. A. Secagem de grãos de milho em secador de leito fixo. Pesquisa Agropecuária Gaúcha, Porto Alegre, v. 9, n. 1/2, p. 8591, 2003.

ELIAS, M. C. Fatores que influenciam a aeração e o manejo da conservação de grãos. In: LORINI, I.; MIIKE, L. H.; SCUSSEL, V. M. (Ed.). Armazenagem de grãos. Campinas: Instituto Bio Geneziz, 2002. p. 311-359.

ELIAS, M. C. Tempo de espera para secagem e qualidade de arroz para semente e uso industrial. 1998. 132 f. Tese (Doutorado em Tecnologia de Sementes) Faculdade de Agronomia Eliseu Maciel, Universidade Federal de Pelotas, Pelotas, 1998.
ELIAS, M. C.; LOPES, V.; GUTKOSKI, L. C.; OLIVEIRA, M.; MAZZUTTI, S.; DIAS, A. R. G. Umidade de colheita, métodos de secagem e tempo de armazenamento na qualidade tecnológica de grãos de trigo (cv. 'Embrapa 16'). Ciência Rural, Santa Maria, v. 39 , n. 1 , p. $25-30,2009$.

DOI: $10.1590 / \mathrm{S} 0103-84782009000100005$.

ELIAS, M. C.; ZIEGLER, V.; ROMANO, C. M.; ALVES, G. H.; PARAGINSKI, R. T.; OLIVEIRA, M. Physicochemical properties and enzymatic bean grains dried at different temperatures and stored for 225 days. Semina. Ciências Agrárias, Londrina, v. 37, n. 3, p. 1295 1306, 2016.

FERRARI FILHO, F.; ANTUNES, L. E. G.; TIECKER, A.; LIMA, R. F. de; DIONELLO,

R. G. Efeito de diferentes fontes energéticas na secagem e de tempos de armazenagem sobre as características físicas e tecnológicas de grãos de milho. Pesquisa Agropecuária Gaúcha, Porto Alegre, v. 20, n. 1/2, p. 68-76, 2014.

FERRARI FILHO, E.; ANTUNES, L. E. G.; TIECKER, A.; DIONELLO, R. G.; SPOLTI, P. Controle de gorgulhodo-milho submetido ao tratamento térmico. Revista Brasileira de Milho e Sorgo, Sete Lagoas, v. 10, n. 3, p. 196-204, 2011.

DOI: 10.18512/1980-6477/rbms.v10n3p196-204.

FERRARI FILHO, E.; ANTUNES, L. E. G.; GOTARDI, R.; DIONEllo, R. G.; PETRY, P. A. R.; BARRETO, G. P. Qualidade de grãos de trigo submetidos a diferentes condições de armazenamento. Pesquisa Agropecuária Gaúcha, Porto Alegre, v. 18, n. 1, p. 25-35, 2012.

FLEURAT-LESSARD, F. Qualitative reasoning and integrated management of the quality of stored grain: a promising new approach. Journal of Stored Products Research, Oxford, v. 38, n. 3, p. 191-218, 2002. DOI: $10.1016 / \mathrm{S} 0022-474 \mathrm{X}(01) 00022-4$.

MARINI, L. J.; GUTKOSK, L. C.; ELIAS, M. C.; MEZZOMO, M. Efeito da secagem intermitente na 
estabilidade de grãos de aveia. Brazilian Journal of Food Technology, Campinas, v. 8, n. 3, p. 260-267, 2005.

MUKANGA, M.; DERERA, J.; TONGOONA, P.; LAING, M. D. A survey of preharvest ear rot diseases of maize and associated mycotoxins in south and central Zambia. International Journal of Food Microbiology, Amsterdam, v. 141, n. 3, p. 213-221, 2010.

DOI: $10.1016 / \mathrm{j}$. ijfoodmicro.2010.05.011.

OLIVEIRA, L. C.; GUTKOSKI, L. C.; ELIAS, M. C.; MAZZUTTI, S.; AOSANI, E.; ROCHA, J. C. Efeito da temperatura de secagem na qualidade de grãos de grãos de aveia branca. Ciência e Agrotecnologia, Lavras, v. 34, n. 2, p. 313-319, 2010.

DOI: $10.1590 / \mathrm{S} 1413-70542010000200007$.

PARAGINSKI, R. T.; ROCKENBACH, B. A.; SANTOS, R. F.; ELIAS, M. C.; OLIVEIRA, M. Qualidade de grãos de milho armazenados em diferentes temperaturas.

Revista Brasileira de Engenharia Agrícola e Ambiental, Campina Grande, v. 19, n. 4, p. 358-363, 2015.

DOI: 10.1590/1807-1929/agriambi.v19n4p358-363.

PARAGINSKI, R. T. Efeitos da temperatura de armazenamento de grãos de milho (Zea mays L.) nos parâmetros de qualidade tecnológica, metabólitos e propriedades do amido. 2013. 109 f. Dissertação (Mestrado em Ciência e Tecnologia de Alimentos) Universidade Federal de Pelotas, Pelotas, 2013.
SANTOS, S. B.; MARTINS, M. A.; FARONI, L. R. A.; BRITO JÚNIOR, V. R. Perda de matéria seca em grãos de milho armazenados em bolsas herméticas. Revista Ciência Agronômica, v. 43, n. 4, p. 674-682, 2012. DOI: 10.1590/S1806-66902012000400008.

SCHUCH, G.; GOTTARDI, R.; FERRARI， E. F.; ANTUNES, L. E. G.; DIONELLO, R. G. Efeitos de dois métodos de secagem sobre a qualidade físico-química de grãos de milho safrinha-RS, armazenados por 6 meses. Semina. Ciências Agrárias, Londrina, v. 32, n. 1, p. 235 244, 2011.

SILVA, J. de S. e (Ed.). Secagem e armazenagem de produtos agrícolas. Viçosa, MG: Universidade Federal de Viçosa, 2008. 560 p.

TIECKER, A.; GUIMARÃES, L. E.; FERRARI FILHO, E.; CASTRO, B.; DEL PONTE, E.; DIONELLO, R. G. Qualidade físico-química de grãos de milho armazenados com diferentes umidades em ambiente hermético e não hermético. Revista Brasileira de Milho e Sorgo, Sete Lagoas, v. 13, n. 2, p. 174-186, 2014.

DOI: $10.18512 / 1980-6477 /$ rbms.v13n2p174-186.

USDA. Foreign Agricultural Service. Production, supply and distribution online. Washington, 2016. Disponível em: $<$ http://apps.fas.usda.gov/psdonline $>$. Acesso em: 20 out. 2016.

WEBER, E. A. Secadores. In: WEBER, E. A. Excelência em beneficiamento e armazenagem de grãos. Canoas: Salles, 2005. p. 155-310. 